\title{
Filho natural e pai ausente: As colónias africanas no imaginário do império português em Os Maias
}

KRISTINA SORIC

The Ohio State University

\begin{abstract}
This article analyzes the role of Africa in José Maria de Eça de Queirós's Os Maias (1888), despite what appears to be a lack of explicit African presence in the novel. By connecting the generations of Maia men with nineteenth-century Portuguese history, Os Maias presents the allegorical depiction of Portugal's struggle for inclusion on the imperial stage after the loss of Brazil, as well as the empire's subsequent turn to Africa as a potential solution. The novel likewise details the abstraction of the African colonies and their subjects within the Portuguese imaginary, in which Africa not only symbolizes the future of the empire and theoretically broadens the borders of the tiny nation, but also becomes the object of paternalistic attitudes that reinforce Portuguese claims to a place among the rest of the modern "civilizing” empires of Europe.
\end{abstract}

Keywords: Imperial discourse; Africa; Eça de Queirós; nineteenth century; filiation/affiliation; Geração de 70

Apesar de a África ocupar um lugar fundamental na política imperial do século XIX em Portugal, a escassez de presença africana na literatura da época é mais um sintoma do seu lugar secundário dentro da consciência social e cultural da metrópole. Como diz Laura Cavalcante Padilha, no imaginário português do século a África existia como "apenas e tão somente uma página em branco ou uma margem vazia, onde não havia homens civilizados, memórias, histórias" (42), um território algures cuja imagem se restringia para os portugueses à fortuna pendente ou à obscuridade dos condenados, desterrados da terra e da 
memória da metrópole. No entanto, em Os Maias de Eça de Queirós, é por meio desta mesma atitude e a sua representação literária que podemos identificar uma relação subjacente e importante entre as últimas colónias e a experiência imperial dos portugueses. Através das gerações dos homens Maia e as suas inseguranças patriarcais, Eça de Queirós reflecte a luta de Portugal para manter o seu lugar no cenário imperial, sobretudo na sombra omnipresente da influência inglesa, mas também dentro da sua própria consciência coletiva. Como solução aos seus sentimentos de inferioridade frente à decadência do império, a metrópole recorre à África, território que não apenas aumenta a riqueza e amplia as fronteiras da pequena nação, senão também a coloca em uma posição paternalista para com os seus habitantes nativos, selvagens e incivilizados nos olhos europeus da época. Neste artigo, demonstro como as contradições deste sistema patriarcal são representadas em Os Maias, embora duma maneira que simultaneamente perpetua estas tendências no momento da sua documentação.

A representação da relação entre pai e filho e a importância desta ligação, embora saliente em Os Maias, transcende as páginas do romance queirosiano como um reflexo do contexto sociopolítico da época em Portugal. Phillip Rothwell pretende examinar o papel do pai-ou melhor dito, da sua ausência ou vazio - na literatura portuguesa a partir do século XIX, indicando a revolução liberal como um momento que levou consigo "profound effects on the legitimacy of the father figure in the service of statehood, because, to some extent, political forefathers became targets of contempt for sons and daughters" (18). O estudo da figura paternal nas obras oitocentistas, embora explorada em termos freudianos e lacanianos no livro de Rothwell, corresponde com os conceitos de "filiação" e "afiliação" descritos por Edward Said e que aparecem em abundância na literatura do século. Segundo Said, destas obras recebemos "the inmistakable impression that few things are as problematic and as universally fraught as what we might have supposed to be the mere natural continuity between one generation and the next," um problema "portrayed in such a way as to stand for a general condition afflicting society and culture together, to say nothing of individual men and women" (16). A dificuldade da relação filiativa, representada pela orfandade, esterilidade, e inclusive pelo parricídio edípiano, leva à necessidade de reconstruir a maneira das pessoas se relacionarem umas com as outras; daí, segundo Said, aumenta-se a ocorrência e a importância das relações afiliativas, "such as guild consciousness, collegiality, professional respect, class, 
and the hegemony of a dominant culture" (20); isto é, as relações que são determinadas não pelos fatores biológicos como é a filiação, senão os da cultura e da sociedade.

Em Os Maias, vemos como as dificuldades da filiação e a mudança subsequente para as relações de afiliação se desenvolvem não apenas nas vidas das personagens, senão também na história do país, que, como afirma Carlos Reis, não se pode separar das personagens do romance ("The Last Novels" 89). Embora Rothwell indique a desilusão após a revolução liberal como o momento que mais desestabilizou a relação entre o povo e a figura paternal do estado, devemos destacar antes os princípios do século, em que ocorrem vários eventos bem mais chocantes na configuração desta relação, e que inaugurou em Portugal o que Eduardo Lourenço chama o "século de existência nacional traumatizada" (25). O abandono do país perpetrado pelo rei Dom João VI, encarnação desta figura paternal, que se transfere com a família real para o Brasil em 1808 frente às invasões napoleónicas, inicia esta época traumática. Ainda com o regresso da coroa para Lisboa, com a revolução liberal de 1820, vemos a continuação da desestabilidade monárquica, primeiro com a independência do Brasil declarada pelo príncipe Dom Pedro em 1822, ato que representa uma ruptura da filiação não apenas biológica, senão também monárquica entre pai e filho, mas também no seu equivalente figurativo entre o rei e a colónia. Na metrópole, o outro irmão Miguel instigará o seu próprio ato de rebelião filiativa contra a constituição aprovada pelo seu pai na forma dos golpes de Vilafrancada e Abrilada nos próximos dois anos. Depois da morte de Dom João VI e o conflito de sucessão subsequente, Dom Miguel impõe-se como rei absoluto em 1828 apesar das condições impostas no seu matrimónio com a filha de Pedro, e começam anos de conflito e guerra civil que não verão o seu fim até a vitória liberal em 1834.

Estes anos de desestablidade total em termos da legitimidade da monarquia e as consequências que manifestam na sua relação com o povo, sobretudo na forma da oposição liberal contra o absolutismo imposto por Dom Miguel em 1828, se personificam em Os Maias na relação entre Afonso e o seu pai. Em Caetano de Maia, "português antigo e fiel que se benzia ao nome de Robespierre" (Eça de Queiros, Os Maias 15), podemos identificar o Portugal tradicional e miguelista que, apesar do poder absoluto, não consegue a lealdade dos seus "filhos": "A gota cruel, cravando-o na poltrona, não lhe deixou espancar o mação, com a sua bengala da India, á lei de bom pai português" (Eça de Queiros, 
Os Maias 15). Frente à incapacidade da autoridade paternal (e, se consideramos a bengala da India, imperial), uma vez suprema, mas já impotente, o único remédio que lhe resta a Caetano, como a Dom Miguel com os revolucionários liberais, é consumar a quebra da filiação e negar-lhe os seus vínculos de origem biológicas e territoriais: "decidiu expulsá-lo de sua casa, sem mesada e sem benção, renegado como um bastardo! Que aquele pedreiro livre não podia ser do seu sangue!" (Eça de Queiros, Os Maias 16)

A simbologia da relação entre pai e filho torna-se concreta quando, como muitos liberais da época, Afonso é oficialmente exilado para Inglaterra, onde estabelece raízes que correspondem à afiliação de Said: "a kind of compensatory order that, whether it is a party, an institution, a culture, a set of beliefs, or even a world-vision, provides men and women with a new form of relationship" (19). Segundo o narrador, Afonso enamora-se da cultura inglesa e instrui-se profundamente na sua história e nas suas tradições, enquanto se desassocia de Portugal e "essa plebe beata, suja e feroz, rolando do lausperene para o curro, e ansiando tumultuosamente pelo príncipe que lhe encarnava tão bem os vícios e as paixões" (17). No entanto, por causa das saudades profundas da sua mulher, vê-se obrigado a voltar para Lisboa com ela e o seu filho, Pedro. Apesar de se introduzir de novo na sociedade portuguesa, porém, vemos que Afonso leva com ele as suas novas inclinações inglesas, tal como fizeram muitos dos exilados à sua volta, segundo Rothwell: "On their return, everything British was chic, and their affection for the British way of life often became yet another way British interests were pursued in the country" (74). Vemos que estas afiliações com todo o britânico são traduzidas também à esfera política, onde os ingleses, cuja protecção durante a invasão napoleónica já tinha deixado Portugal numa relação de dependência, veriam os seus interesses ainda mais acomodados na Regeneração, na qual "the very radicals of Afonso in his youth . . became the forces who sold the country and its traditions out to the interests of the British and their empire" (Rothwell 67).

Boaventura de Sousa Santos descreve esta relação de dependência portuguesa do poder económico e político da Inglaterra, a qual coloca Portugal numa posição de "semiperiferia" na Europa; apesar da sua própria expansão imperial, sob as pressões capitalistas dos ingleses, Portugal torna-se numa "colónia informal" da Inglaterra, e passa da sua posição como portador de cultura e comércio a ser apenas uma "correia de transmissão" entre as suas próprias 
colónias e os outros países europeus, sobretudo a Inglaterra, que aproveitam dos seus recursos (11). No entanto, segundo Sousa Santos, é graças a esta posição geográfica entre o continente e o horizonte que permite Portugal, até hoje, se imaginar parte do centro. Margarida Calafate Ribeiro elabora as observações de Sousa Santos para estudar mais profundamente o processo de descentralização na época colonial, formando o seu próprio conceito do "império como imaginação do centro," em que "Portugal existia através do seu império e, através dele, imaginava-se centro" (13). A dependência de Portugal não apenas da Inglaterra, senão também das suas colónias, leva ao que Calafate Ribeiro descreve como "um Portugal esvaziado, distante da ideia da ciência do século, manipulado ao sabor dos interesses estrangeiros e sem força e alma de aventura" (14), um sentimento que chegará ao seu auge com Eça de Queirós e os outros intelectuais da Geração de 70 nas últimas décadas do século. Lourenço sintetiza estes conceitos sociopolíticos em conjunto à literatura portuguesa, e justamente com a que nos interessa aqui, descrevendo o "itinerário da nossa intrínseca subalternidade e dependência, cujo drama com laivos offenbachianos será descrito - ao mesmo tempo que exemplificado - pela obra mais típica e mais trágica do nosso Romantismo sarcástico, mascarado de realismo: a de Eça de Queirós" (54).

Em Os Maias, este processo de descentralização e esvaziamento desenrolase simbolicamente através da relação entre Afonso e o seu filho, Pedro, e logo também com o seu neto, Carlos. Apesar de Afonso desejar para Pedro uma educação ao estilo inglês, isto é, segundo ele, "crear a saude, a força e os seus hábitos, desenvolver exclusivamente o animal, armá-lo duma grande superioridade física" (67), os esforços da sua mulher prevalecem e Pedrinho recebe uma educação sumamente tradicional e católica, focada nas virtudes da alma; o resultado é uma exagerada disposição romântica que reflete a geração literária que precedeu a Geração de 70, e cuja "utilização 'doentia' do amor pátrio" como degradação do nacionalismo de Almeida Garrett e Alexandre Herculano foi denunciada por Eça de Queirós (Castro 18). Em Pedro de Maia, vemos personificados os rasgos românticos e, no seu luto da morte da sua mãe, a idealização desesperada do país decadente que critica Eça: "Era tudo um fraco; e esse abatimento contínuo de todo o seu ser resolvia-se a espaços em crises de melancolia negra, que o traziam dias e dias mudo, murcho, amarelo, com as 
olheiras fundas e já velho. O seu único sentimento vivo, intenso, até aí, fora a paixão pela mãe" (Os Maias 22).

Neste Pedro fraco e as suas relações amorosas, vemos um processo muito semelhante aos esforços nacionais de recuperar o seu lugar central na Europa, através da "busca do outro, para, por essa arrancada, criar fora a grandeza que lhe faltava dentro" (Cavalcante 29). Vemos este sentimento representado na consolação que encontra Afonso a saber que, apesar da natureza frágil do seu filho, pelo menos, "teve o seu bastardozinho" (Eça de Queiros, Os Maias 22). O leitor nunca conhece nada do filho ilegítimo nem da sua mãe, e longe de se escandalizar com a notícia, Afonso a vê como sinal da virilidade que deseja ver no seu filho mimado, contanto que não estabeleça uma relação oficial com a amante. Vemos na atitude patriarcal da sociedade aristocrática, demonstrada no comportamento de Pedro e na reação de Afonso, uma perspectiva muita parecida àquela que funda a relação de Portugal com África, "uma vaga terra distante, ligada a escravos, doenças e degredo de onde chegavam . . . notícias de guerras com que Portugal procurava afirmar uma estratégia geopolítica, local e internacional; determinante para o seu lugar em África e o seu correspondente peso na 'balança da Europa"' (Calafate Ribeiro 16). A África, como o "bastardozinho" de Pedro, existe no imaginário nacional somente para apoiar a imagem dum Portugal poderoso, à custa das injustiças associadas com o sistema que são reconhecidas apenas a um nível abstracto; como afirma Afonso, "Os costumes são assim e a vida é assim, e seria absurdo querer reprimir tais coisas" (Eça de Queiros, Os Maias 29). Tal como se negará a legitimidade da filiação (junto com todos os seus privilégios materiais e sociais) ao filho que prova a mesma masculinidade de Pedro no sistema patriarcal da época, Portugal estabelecerá na África um sistema afiliativo com, como explica Said, "the deliberately explicit goal of using that new order to reinstate vestiges of the kind of authority associated in the past with filiative order" (19). Através das colónias africanas, o império pretenderá reestabelecer o seu lugar como poder central entre os outros impérios e figura paternal dentro do seu próprio, embora fora da terra portuguesa e, como demostraremos mais tarde, duma maneira que prejudicará os africanos tanto quanto os mesmos portugueses.

O matrimónio de Pedro também reflete o intento, às vezes paradoxal, do império se reinserir entre os poderes dominantes da Europa, sobretudo na estima da Inglaterra. À chegada da sua futura esposa a Lisboa, toda a cidade se 
escandaliza ao saber que é filha dum traficante de escravos, e Afonso também reprova da ideia de Pedro se associar com ela, ainda como amante, porque "ela é a filha de um assassino, de um negreiro, a quem chamam negreira" (Eça de Queiros, Os Maias 32). Segundo Rothwell, esta reação forma parte da afiliação de Afonso com a Inglaterra, que representa para ele e os outros liberais "modernity, pragmatism, an empire that functioned, and loosely democratic values. . . As such, it was always in opposition to something negative about the Portuguese" (75). Não surpreende, pois, que Afonso tenha uma reação tão forte à história de Monforte, que se esquivava durante anos os cruzadores ingleses que pretendiam dar fim ao tráfico humano, e representava para Afonso a vergonha da barbaridade do seu país aos olhos dos ingleses. No entanto, diz Rothwell, Afonso não reconhece a contradição da sua própria situação dentro deste sistema: "Papa Monforte embodies the hideousness of selling slaves - the grossness of the appearance, yet the wealth from which Afonso's nobility benefits, as a member of a family that has never had physically to work, is the sanitized, disembodied, alienated and alienating side of Monforte's trade" (76).

De facto, depois de Maria Monforte se casar com Pedro e voltar para Portugal, a sociedade lisboeta muda de opinião logo que o casal começa a dar festas opulentas e populares, “chamando-lhe 'querida,' admirando as grinaldas de camélias que emolduravam os espelhos de quatrocentos mil réis, e gozando muito os gelados" (Eça de Queiros, Os Maias 38). Vemos nestas ocasiões como os princípios éticos para com a escravatura não transcendem as meras aparências dentro da sociedade acomodada, que se deixa seduzir pelos seus benefícios, apesar dos meios pelos quais são adquiridos; um sentimento muito semelhante ao que motivaram as políticas abolicionistas "para inglês ver" da época que davam a aparência de práticas mais humanas, mas que em realidade não mudaram os comportamentos dos traficantes e colonos. João Pedro Marques explica a natureza superficial deste processo, afirmando: "É certo que o Príncipe Regente D. João assinou, logo em 1810, uma das primeiras joint ventures de política anti-tráfico com a Grã Bretanha. . . . O objectivo final, porém, e atendendo à posição do Brasil, era o da manutenção do tráfico pelo máximo tempo possível" (98). Ainda com a independência do Brasil e a intensificação do rigor inglês frente aos traficantes ilegais, "o fluxo negreiro entre a África meridional portuguesa e o Brasil— de longe o grande sorvedouro de Africanos, 
absorvendo mais de 80 por cento da importação total—manteve-se em pleno até 1850" e continua depois com Cuba até 1862 (98).

A tenacidade do tráfico de escravos e a consequente dependência nas colónias africanas representam uma das tendências descritas por Calafate Ribeiro que se manifestam em Portugal depois da traumática perda do Brasil. Explica que a imagem do império português se dividiu em duas ramas que dominaram os debates sobre as colónias que restavam na África: "o sonho português imperial", que evocou as glórias do Portugal do centro e dos Descobrimentos e, ao contrário, o "sonho europeu", visão portada pela Geração de 70 que "apontava para um novo modelo de desenvolvimento de Portugal, consubstanciado na reterritorialização e mesmo na venda das colónias, para rumar a uma aproximação de Portugal ao grande desenvolvimento das nações da Europa" (15). Este grupo de intelectuais, formado em parte por estudantes de Coimbra mas também com alguns de fora, buscava nas ideias da Europa moderna - a ciência positivista, a literatura realista, as ideias socialistas e republicanas - uma revolução cultural para dar arranque à entrada de Portugal na época moderna e assim regenerar o país atrasado. A visão do grupo se concretizou nas Conferências Democráticas do Casino Lisbonense, onde Eça de Queirós, Oliveira Martins, Antero de Quental, Teófilo Braga, entre outros, projectaram a revolução cultural por vir; no entanto, as críticas contra a igreja, a corrupção política, e a velha sociedade que também foram expressas nas Farpas de Eça e Ramalho Ortigão levaram à proibição das conferências e a frustração do grupo. Adalmir Leonidio descreve os resultados desta frustração na mentalidade da geração:

O primeiro impulso da "geração de setenta" gerou improfícuos resultados, e o grupo, reunindo-se casualmente e a propósito de circunstâncias várias, jamais conheceria a coesão inicial e a afinidade de propósitos. Ficava a sensação de impotência, de incapacidade do homem, determinado por férreas leis naturais, para resolver os seus problemas. (20)

Apesar dos intentos de seguir com o seu projeto, que incluíam a criação da Revista de Portugal em 1889, a visão do grupo manteria o tom pessimista que, nos anos 90, levará a uma renúncia das ideias revolucionárias e a mudança correspondente do nome de grupo para os "Vencidos da Vida." 
Em Os Maias, escrito na década entre a do lançamento optimista da Geração de 70 e a da expressão oficial do pessimismo dos Vencidos, vemos a representação do fracasso da geração personificado nas personagens de Carlos e Ega, que também buscam revolucionar a sociedade portuguesa através da ciência e da literatura. Vemos exemplificada em Carlos a imitação por excelência da cultura moderna, em que Inglaterra serve como modelo da Civilização. O seu próprio nome representa outra negação da ordem filiativa em termos da família Maia e da nacionalidade portuguesa; esta vez, ironicamente, é o nome de Afonso que é rejeitado em favor do último Stuart da Inglaterra. Portanto, segundo Rothwell, "Carlos's naming portends a surrender of his character to all things British, and a deliberate affront to Portuguese tradition that Alfonso would later compound through his education of the young Carlos" (70). Veremos que a educação inglesa do neto de Afonso, embora cumpra o desejo que lhe foi negado na formação do seu próprio filho, apenas acaba por criar em Carlos "a character who encapsulates a failed attempt to 'Anglify' as an antidote to Portugueseness" (74). Podemos indicar a vários níveis as falhas deste personagem limitada: a sua relação incestuosa com Maria Eduarda, o seu abandono da carreira médica e o seu fracasso como escritor, e por fim a incapacidade procriadora descrita por Said e tão saliente na literatura do século. Lourenço descreve eloquentemente como a impotência de Carlos e Ega exemplificam a esterilidade das ideias importadas pela Geração de 70 dentro da sociedade Portuguesa:

Era uma ausência concreta, ou se se prefere a realidade da sua espessa passividade cívica e cultural, pelo menos da Cultura afinada pelos Michelet, os Renan, os Hegel, que os Egas e os Carlos da Maia liam, ou não liam. Ou liam como se não lessem apenas para cavar mais fundo o complexo de analfabetos em perpétuo atraso ou de veleitários imitadores do avanço científico dos outros a quem como Carlos se compram tratados e aparelhagem médica para os deixar cobrir por teias de aranha num laboratório abandonado. (54)

Por trás da presença ubíqua da influência inglesa em Portugal e o fracasso da sua implementação no país existe a crítica de Eça de Queirós, para quem, segundo Rothwell, "The British and their empire meant, for Eça at least, a nefarious, brutal and corrupting presence in cultures that the Victorians did not understand" (71). 
Vemos este sentimento expresso claramente em "Os ingleses no Egipto" das Cartas de Inglaterra, em que Eça denuncia "o seu pé de ferro, essa enorme pata anglo-saxonia, que, uma vez pousada sobre território alheio, seja um rochedo como Gibraltar, uma ponta de areia como Anden, uma ilha como Malta, ou todo um mundo como India — nenhuma força humana pode jamais arredar ou mover" (IV). É esta visão da Inglaterra tirânica e hipócrita, que também aproveitou da escravatura nas suas colónias e na metrópole para a logo condenar em apoio do desenvolvimento do seu sistema capitalista, que Eça critica nas Cartas mas também na moralidade hipócrita de Afonso e da nobreza de Lisboa para com os Monforte, que, segundo Rothwell, apenas representam o rosto visível do mesmo processo oculto no fundo do processo imperial da Inglaterra (77).

Ademais da simples crítica da imitação portuguesa dos ingleses em termos das ideais culturais, Os Maias também critica as políticas do império português que, ao mesmo tempo que procuram manter as colónias africanas para competir com a Inglaterra e demais potências europeias, exibe a mesma hipocrisia e tirania dos ingleses criticada por Eça nas suas Cartas. Não surpreende que esta crítica apareça nas duas obras, como ambas foram escritas durante a mesma visita do autor a Inglaterra que, podemos supor, lhe ofereceu não simplesmente a oportunidade de ver Portugal com uma distância crítica, senão também desde o mesmo país em que, segundo Sousa Santos, "the 'Black Legend' of Portugal and the Portuguese among the British as a fallen, degenerate, and imbecile people becomes more consistent" (21). Embora fala de outro escritor no seu comentário, o que diz Said sobre a experiência do exílio pode-se aplicar ao tempo que passou Eça na Inglaterra, que também representa "an instance of both filiation with his natal culture and, because of exile, affiliation with it through critical consciousness and scholarly work" (16); instância em que o português poderia reconhecer as semelhanças entre as políticas e atitudes do império britânico para com Portugal, e as do império Português para com os africanos. Ao reconhecer estas semelhanças que aparecem no romance, podemos dar resposta à interrogação de Rothwell quando pergunta, "But what happens when we do not like, or more pointedly, when we loathe what we see in the Other that is in ourself?" (66); embora uma resposta ligada não à análise psicoanalítica de Rothwell, senão à "symmetry between the Northern European stereotypes of the Portuguese and the Northern and Southern European stereotypes of the indigenous people of Africa and America" referido por Sousa Santos (23). 
Lourenço explica como a fractura da imagem do Portugal como centro e como periferia leva a nação a exibir simultaneamente um complexo de inferioridade e de superioridade, e como, "Segundo as contingências da situação internacional ou mundial, aparece ao décimo um ou outro complexo, mas com mais constância os dois ao mesmo tempo, imagem inversa um do outro" (19). Esta dualidade se expressa claramente nas personagens de Os Maias que, como o império, se voltam para a África como substituição não apenas do lugar económico do Brasil, senão também do seu papel dentro do imaginário do império como centro através da sua relação afiliativa, como explica Calafate Ribeiro. Vemos este fenómeno na reação do conde de Gouvarinho, que, ao ler o livro do inglês, Major Bratt, que critica o império português, "via ali só invejaa inveja que nos têm todas as nações por causa da importância das nossas colónias, e da nossa vasta influencia na África," afirmando também que "não há hoje colónias nem mais susceptíveis de riqueza, nem mais crentes no progresso, nem mais liberais que as nossas!" (Eça de Queirós, Os Maias 397). Por outro lado, João da Ega expressa a visão oposta dos portugueses como "a mais fraca, a mais covarde raça da Europa" (Eça de Queirós, Os Maias 174), para quem as colónias apenas servem "como a prata de família aos morgados arruinados, para ir empenhando em casos de crise" (Eça de Queirós, Os Maias 171). Esta avaliação dos territórios africanos reflecte a mesma opinião do Eça de Queirós dos anos 70, expressada nas Farpas que escreve durante esta época e logo publica na colecção Uma Campanha Alegre. Em Julho de 1871, junto com a mesma sugestão de vender as colónias, Eça também comenta a sua inutilidade aparte do nível simbólico duma maneira semelhante às criticas de Ega: "Quando muito, às vezes, a Metrópole remete às colónias um governador: agradecidas, as colónias mandam à mãe-pátria - uma banana. E perante este grande movimento de interesses e de trocas, Lisboa exclama: 'Que riqueza a das nossas colónias! Positivamente, somos um povo de navegadores!"' (XVIII).

No entanto, entre os numerosos "paradoxos do nosso Ega" (Eça de Queirós, Os Maias 171), o seu complexo de inferioridade vai acompanhado por uma atitude paternalista para com os africanos, que o deixa manter simultaneamente o complexo de superioridade referido por Lourenço. Num momento exemplar, em que João comenta a importação das ideias europeias, diz que "tudo nos vem em caixotes pelo paquete. A civilização custa-nos caríssima com os direitos da alfândega: e é em segunda mão, não foi feita para nós, fica-nos curta nas 
mangas"; ao que agrega uma afirmação da inferioridade e superioridade simultâneas que caracterizam os brancos portugueses: 'Nós julgamo-nos civilizados como os negros de São Tomé se supõem cavalheiros, se supõem mesmo brancos, por usarem com a tanga uma casaca velha do patrão" (Eça de Queirós, Os Maias 114). Vemos esta atitude expressa como parte da arbitrariedade da sua personalidade dandy e as suas opiniões inflamatórias e extremas, que muitas vezes parece soltar apenas para escandalizar os outros. Esta representação evoca uma caricatura da mentalidade de Geração de 70 que o mesmo Eça de Queirós comenta na sua reedicão do seu primeiro romance, $O$ Mistério da estrada de Sintra (1884), mais de uma década depois da sua publicação original. No prefácio à terceira edição, Eça critica o romance desde a perspectiva dos "velhos escritores, que há muito desviaram os seus olhos das perspectivas enevoadas da sentimentalidade, para estudarem pacientemente e humildemente as claras realidades da sua rua" (7); porém, defende dalguma maneira a "loucura espiritual" na mocidade dele e dos outros da sua geração: "Aos vinte anos é preciso que alguém seja estroina, nem sempre talvez para que o mundo progrida, mas ao menos para que o mundo se agite" ( $O$ Mistério 7).

Esta atitude manifesta-se claramente em João da Ega, que serve como contrário ao passivo e indeciso Carlos de Maia. Nos seus comentários nas reuniões com Craft, Gouvarinho e Alencar, Ega, como o Papá Monforte, representa o rosto realista do colonialismo que se esconde no discurso imperial da Inglaterra tanto quanto de Portugal. À afirmação do progresso e liberalismo das colónias portuguesas enunciada pelo conde, João da Ega declara que está em favor da escravatura, e afirma que:

Só podia ser seriamente obedecido, quem era seriamente temido. . . . Só houvera duas civilizações em que o homem conseguira viver com razoável comodidade: a civilização romana, e a civilização especial dos plantadores da Nova Orleães. Porquê? Porque numa e noutra existira a escravatura absoluta, a sério, com o direito de morte! (Eça de Queirós, Os Maias 398)

Esta afirmação, à parte sua natureza extrema e escandalosa, reflete as proposições de outro membro da Geração de 70 e amigo íntimo do nosso autor, o historiador Oliveira Martins. Na introdução de O Brasil e as colónias portuguesas, Martins descreve a sua visão da história ditada pelas leis darwinistas, nas quais a 
dominação colonial, "o morticínio de uma tribu indígena, o desembarque das mulheres vindas do reino, ou o rapto das dos indios; cada um d'esses factos acorda no espirito do observador o conducto de condições e de leis a que obedecem o nascer e o crescer das sociedades" (viii); e num gesto que evoca ainda mais as palavras de Ega, termina a introdução com uma citação da História da república romana: "assim Roma se tornou a maravilha do mundo!" (viii).

Vemos claramente na atitude de Martins a manifestação do mesmo complexo descrito por Lourenço e exibido por Ega, mais ao nível nacional. Enquanto Ega encontra o sentimento de superioridade pessoal na sua atitude paternalista para com os africanos, Oliveira Martins busca, através da afiliação, como diz Said, "restored authority" na relação colonial entre Portugal e a África, na qual esta autoridade "is greater than the individual adherent or member, just as the father is by virtue greater than the sons and daughters" (19). A visão paternalista de Oliveria Martins se faz bem clara no seu desejo de "explorar em proveito nosso o trabalho de uns milhoes de braços, enriquecendo-nos à custa d'elles" (233), como se fez na fundação do Brasil. Inclusive comenta as atitudes moralistas da época como derivadas da hipocrisia do império britânico que ele, como Ega, demonstra abertamente, dizendo, "Porventura a franqueza com que estas cousas são ditas magoará muitos ouvidos educados pelas notas ingenuas ou hypocritas da idolatria do nosso século" (234); como resposta, desenvolve toda uma teoria que afirma a impossibilidade de civilizar o africano, "typo anthropologicamente inferior, não raro próximo do anthropoide, e bem pouco digno do nome de homem" (284), em favor dum sistema de trabalho forçado que, numa visão que exemplifica o paternalismo desenfreado, é a única maneira de integrar ao império "uma creança adulta" cujas "qualidades infantis não se transformam em faculdades intelectuais e superiores" (283-84).

A mesma rejeição do intento de "civilizar" o africano aparece em Os Maias, quando Ega insiste que é contra as missões civilizadoras:

Porque não se deixaria o preto sossegado, na calma posse dos seus manipanços? Que mal fazia para a ordem das coisas se houvesse selvagens? Pelo contrário, davam ao Universo uma deliciosa quantidade ao pitoresco! . . . Dentro em breve um touriste faria enormes sacrifícios, despesas sem fim, para ir a Tangubutu - para quê? Para encontrar lá pretos de chapéu alto, a ler o 'Jornal dos Debates.' (Eça de Queirós, Os Maias 397-98) 
Enquanto Ega rejeita a educação dos africanos por motivos de novidade e do pitoresco, em fim, para o entretimento do homem de bem, Oliveira Martins, junto a sua crença na incapacidade intelectual do africano, vê nos intentos ingleses de civilizar a África outra hipocrisia na forma da oportunidade capitalista: "Apostolos e missionarios da ideia nova e negra, colloquemo-nos ao lado dos inglezes, chamamos o preto à escola, baptizeml-o, moldemol-o à europêa, e a Africa será grande. ... E Angola e Moçambique o quê? O mercado dos algodões inglezes, com que vestirão as suas vergonhas os pretos civilizados" (Eça de Queirós, Os Maias 238). Nesta crítica mordaz, vemos como os comentários maliciosos do malandro Ega se levam ao nível do discurso imperial, motivado simultaneamente pela noção da superioridade dos portugueses sobre os africanos, e o seu complexo de inferioridade para com os ingleses.

No desejo de Ega de "deixar o preto sossegado," porém, podemos detectar uma nota da ironia queirosiana, sobretudo se consideramos que este comentário é seguido imediatamente pelo seu argumento em favor da escravatura e em contra do Progresso. Ademais, com os comentários de Ega minimizadas como "paradoxos" risíveis, a conversação muda para a Sociedade Protectora dos Animais, a qual, segundo Sousa Neto, era um dos "progressos" mais úteis "de todas as sociedades que ultimamente se têm fundado entre nós, à imitação do que se faz lá fora" (400-01). Nesta referência irónica à progressividade de proteger os animais momentos depois de esquivar os comentários inflamatórios de Ega sobre a escravidão, vemos como ao mesmo tempo a sua disposição maldosa, junto com a anulação de qualquer debate do tema desagradável da escravatura entre a classe dirigente, incapacita a possibilidade duma discussão produtiva sobre o assunto. Como o traje do "selvagem" que o amigo de Carlos veste para a festa dos Gouvarinho, o africano existe nestas conversas como uma imagem abstrata que ornamenta as reuniões de gente privilegiada, e que se evoca apenas como evidência do "progresso" ou do "chic," senão simplesmente como piada.

Destes momentos irónicos, podemos reconhecer em Carlos e em Ega a representação das contradições indicadas por Eça de Queirós na mocidade sentimental e "loucura espiritual" da sua geração. A descrição de Cavalcante Padilha de A Ilustre casa de Ramires também se pode aplicar a Os Maias, quando ela o caracteriza como um texto "simbólico e sintomático das tensões do Portugal finissecular," pelo qual "é natural que nele a questão do império colonial se narrativize por brechas, fissuras e, muitas vezes, por silêncios, de acordo com o 
imaginário político do tempo" (37). Em outro momento do romance, Eça ilustra como as preocupações sentimentais de Carlos o impedem de ver a situação africana através de uma perspectiva que não seja a versão fragmentada de Portugal, quando visita a casa da sua amante, a Gouvarinho, e "em lugar dos cabelos crespos e ruivos, avistou a carapinha retinta de um preto, um preto de doze anos, trombudo e luzidio" (Eça de Queirós, Os Maias 140). Apesar da sua curiosidade para com o rapaz africano e o outro que o acompanha, Carlos não fala com eles, nem pergunta sobre a sua presença; e, ainda mais indicativo da sua mentalidade obscurecida, "pouco a pouco, aquele preto de que os seus olhos se não podiam despegar, ali entronizado na poltrona de reps verde da Gouvarinho . . . foi-lhe arrastando, a seu pesar, a imaginação para a pessoa dela" (Eça de Queirós, Os Maias 140-41). Por fim, a sua curiosidade supera o seu devaneio amoroso, e Carlos pergunta-se, "Quem seriam, por que estavam ali, aqueles africanos de perfil trombudo?"(Eça de Queirós, Os Maias 141); no entanto, num exemplo dos silêncios queirosianas que menciona Cavalcante Padilha, Carlos não persiste nas suas contemplações nem tenta saber mais sobre os rapazes, e simplesmente comenta a sua "extraordinária carapinha" para o outro português na sala antes de sair.

Os comportamentos e perspectivas de Carlos e Ega evocam a imagem de outra figura queirosiana que também representa a mentalidade da sua geração: Fradique Mendes. Reis identifica-o como "uma personagem-chave de toda a Geração de 70, uma espécie de arquétipo" que, como os protagonistas de Os Maias, "representa a desistência política da Geração de 70, manifesta na última fase da vida de Eça de Queirós" ("Os Silêncios de Eça" 71-72). Em $A$ Correspondência de Fradique Mendes, Eça exemplifica a visão da sua geração, ditada pelos discursos "eurocêntricos, por sua natureza intrínseca absurdamente autocentrados e narcísicos" com a personagem de Fadrique (Cavalcante Padilha 36), que, apesar de viajar pelo mundo inteiro em busca dum lugar livre da contaminação europeia, irónica e paradoxalmente percebe a mesma falta da cultura europeia na África como a falta absoluta de cultura. Com uma perspectiva que paralela as preocupações sentimentais e artísticas de Ega e Carlos, Fradique recusa escrever um livro sobre a viagem por causa desta "falta" de cultura na África, e também por causa das suas próprias teorias abstratas sobre as capacidades representativas da escritura: "Não vi nada na África que os outros não tivessem visto. . . . Só podia apresentar uma série de impressões, de 
paisagens. E então pior! Porque o verbo humano, tal como falamos, é ainda impotente para encarnar a menor impressão intelectual, ou reproduzir a simples forma dum arbusto" (Eça de Queirós, A Correspondência 105). Não é simplesmente o dilema estético de Fradique, chamado por Carlos Reis a "poética fradiquista", que o impede de reconhecer a cultura africana e escrever sobre ela, senão os discursos eurocêntricos descritos por Cavalcante Padilha, que a ocultavam.

A consequência da mentalidade europeizada de Fadrique é a mesma indicada por Reis como resultado da sua "sublime ambição de só produzir verdades absolutamente definitivas, por meio de formas absolutamente belas" (Eça de Queirós, A Correspondência 106): "o silêncio, esse mesmo silêncio que um Fradique sem obra legou à posteridade" (Eça de Queirós, A Correspondência 34). No caso de Carlos da Maia, é especificamente essa falta de visão original que causa a sua impotência literária tanto quanto procriadora, símbolo da frustração da Geração de 70 que nunca cumpriu a revolução que desejara. No entanto, na literatura de Eça de Queirós, a representação da mentalidade da sua geração para com as colónias africanas é também expressa através do silêncio, "simbólico e sintomático," como diz Cavalcante Padilha (37). Reis descreve como o silêncio, embora distinto do silêncio fradiquista, forma parte da poética do mesmo Eça: "Como Fradique, mas também diferentemente dele-num jogo de ambivalências, de sombras e de disfarces que talentosamente soube encenar, Eça de Queirós está próximo e está longe de uma poética do silêncio" ("Os Silêncios de Eça" 34). No caso de $A$ cidade e as serras e A Ilustre casa de Ramires, José Carlos Siqueira pretende explicar este silêncio como a representação do "horror" inapreensível da África, ao estilo de Joseph Conrad, que Eça não pode representar (204), enquanto Graça Videira Lopes atribui esta incapacidade à sua falta de conhecimento e experiência pessoais nas colónias; no entanto, em Os Maias, uma reflexão do autor sobre a mentalidade da sua geração, este silêncio forma parte da realidade do discurso oitocentista e, portanto, do romance também.

Pode-se ver como a presença silenciosa da África em Os Maias é expressa através das mesmas ambivalências e sombras referidas por Reis e que fazem que a obra pareça caber entre a maioria da literatura do século XIX — esta literatura que instiga Said a perguntar "why so few 'great' novelists deal directly with the major social and economic outside factors of their existence-colonialism and 
imperialism - and why, too, critics of the novel have continued to honor this remarkable silence" (177). No entanto, o "silêncio" dos escritores, neste caso de Eça de Queirós em Portugal, é contingente no silêncio dos seus críticos, que têm a responsabilidade de buscar a influência e os indícios das colónias africanas na consciência e na literatura da nação, ainda quando os mesmos portugueses da época não os reconhecem. O espaço colonial, embora exista como "página em branco" na mentalidade portuguesa do século XIX, acaba por conter todas as inseguranças nacionais frente à filiação historicamente problemática com o seu próprio governo, a decadência do império e a imposição externa da Inglaterra e logo dos outros países europeus. Estas inseguranças culminam nas tentativas de compensação por parte da metrópole na forma da sua relação afiliativa com as colónias e os lucros que resultam delas, e na sua atitude paternalista para com os habitantes dum continente que, embora na sua forma mais abstrata e silenciosa, acaba por ocupar um lugar vital no imaginário do império que foi uma vez parte do centro e que luta por se ver ainda como tal.

\section{Obras Citadas}

Bidarra Pinto de Castro, Clementina de Fátima. Reaportuguesar Portugal: o sentido patriótico em Eça de Queirós. Tese. Lisboa: Universidade Aberta, 2008. Impresso.

Calafate Ribeiro, Margarida. "Uma história de regressos: Império, guerra colonial e pos-colonialismo." Oficina do CES 188 (2003): 1-40. Impresso.

Cavalcante Padilha, Laura. "O espaço colonial e sua paginação em branco na cartografia ficcional de Eça de Queiróz." Portugal não é um país pequeno. Ed. Manuela Ribeiro Sanches. Lisboa: Cotovia, 2006. 29-42. Impresso.

Eça de Queirós, José Maria de. A Correspondência de Fradique Mendes. Porto: Lello, 1966. Impresso.

-. Cartas de Inglaterra. Porto: Lello, 1905. Impresso.

—. Os Maias: Episódios da vida romántica. Lisboa: Livros do Brasil, 2006. Impresso.

-. O Mistério da Estrada de Sintra. Lisboa: Texeira, 1947. Impresso.

—. Uma Campanha Alegre. Porto: Porto, 2003. Impresso.

Leonido, Adalmir. "Os Vencidos da vida: Literatura e pessimismo em Portugal no século XIX.” Via Atlântica 6 (2003): 13-28. Impresso. 
Lourenço, Eduardo. O Labirinto de saudade: Psicanálise mítica do destino português. Lisboa: Gradiva, 1991. Impresso.

Manuel Machado, Álvaro. A Geração de 70: uma revolução cultural e literária. Lisboa: Instituição de Cultura e Língua Portuguesa, 1986. Impresso.

Marques, João Pedro. "Uma revisão crítica das teorias sobre a abolição do tráfico de escravos português.” Portugal e a partilha do mundo 14 (1994): 95-118. Impresso.

Oliveira Martins, Joaquim Pedro de. O Brazil e as colónias portuguezas. Lisboa: Parceria Antonio Maria Pereira, 1920. Impresso.

Reis, Carlos. "Os Silêncios de Eça." Eças e outros: diálogos com a ficção de Eça de Queirós. Ed. Regina Zilbermen e Maria da Glória Burdini. Porto Alegre: EDIPUCRS, 2000. 21-35. Impresso.

- "The Last Novels of Eça de Queirós: Realism as a Problem." Portuguese Studies 14 (1998): 84-91. Impresso.

Rothwell, Phillip. A Canon of Empty Fathers: Paternity in Portuguese Narrative. Lewisburg, PA: Bucknell UP, 2007. Impresso.

Said, Edward. The World, the Text, the Critic. Cambridge, MA: Harvard UP, 1983. Impresso.

Santos, Boaventura de Sousa. "Between Prospero and Caliban: Colonialism, Postcolonialism, and Inter-Identity." Luso-Brazilian Review 39.2 (2002): 943. Impresso.

Siqueira, José Carlos. "Eça de Queirós e a representação do horror na colonização africana." Polofonia 19.26 (2012): 190-205. Impresso.

Videira Lopes, Graça. "'Gente preta': África na literatura portuguesa do século XIX." Dimensões da alteridade nas culturas da língua portuguesa: O Outro. Lisboa: U Nova de Lisboa, 1987. Impresso. 265-76. Impresso. 